\title{
RANCANG BANGUN APLIKASI PENCARIAN ALAMAT DI KABUPATEN KUNINGAN BERBASIS MOBILE
}

\author{
Dadang Hamdani ${ }^{1}$, Cristianto ${ }^{2}$ \\ Fakultas Ilmu Komputer Universitas Kuningan \\ Jalan Tjut Nyak Dhien Cijoho Kuningan Telepon (0232) 873696 Fax. (0232) 874824 \\ dadang.hamdani@gmail.com ${ }^{1}$,cristianto208@gmail.com ${ }^{2}$
}

\begin{abstract}
Abstrak
Teknologi WAP merupakan sebuah metode untuk menghadirkan halaman web di dalam handphone. Dengan begitu, informasi tidak harus di tampilkan dengan web yang hanya dapat di akses melalui browser, akan tetapi dapat ditampilkan dalam bentuk WAP. Dengan berkembangnya teknologi WAP, penulis mencoba membuat program aplikasi berbasis mobile untuk pencarian alamat di Kabupaten Kuningan. Aplikasi WAP ini berisi informasi mengenai alamat-alamat di Kabupaten Kuningan dengan menggunakan fasilitas pencarian yang digunakan untuk mengetahui alamat-alamat tersebut. Aplikasi WAP ini dibuat dengan menggunakan bahasa pemrograman WML dan PHP serta MySQL, sebagai databasenya. Pengguna system ada dua yaitu admin dan user, admin akan berinteraksi dengan system melalui browser pada handphone. Pada sistem ini, arsitektur perangkat lunak yang digunakan berupa client-server dan web based, di mana semua data disimpan di web server. Untuk administrator melakukan pengaksesan data yang ada di server secara on-line melewati halaman web dengan menggunakan aplikasi desktop pada perangkat PC. Sedangkan untuk user, dapat mengakses data yang ada di server tersebut secara on-line dengan mengunakan handphone yang memiliki fasilitas WAP dan GPRS yang dimilikinya.
\end{abstract}

Kata kunci : WAP, GPRS, Pencarian, PHP, MySQL

\section{Pendahuluan}

Teknologi yang berkembang pesat beberapa tahun terakhir yang sangat berpengaruh terhadap kehidupan jutaan manusia adalah internet dan handphone / telepon genggam. Internet memberikan kemudahan dalam mengakses informasiinformasi yang sangat berharga dengan biaya murah dan tidak tergantung pada lokasi sedangkan handphone dapat menghubungkan jarak yang begitu jauh untuk berkomunikasi. Penggabungan dua teknologi tersebut memungkinkan untuk mengakses informasi dan lokasi akses.

Semakin pesatnya pembangunan fasilitas umum khususnya di kabupaten Kuningan membuat kebutuhan masyarakat terhadap informasi tentang alamat-alamat fasilitas umum semakin banyak khususnya masyarakat yang berada di daerah terpencil yang umumnya tidak tahu karena tidak ada informasi seperti peta atau selebaran lainnya. Dewasa ini sebagian besar orang sudah memiliki handphone untuk berkomunikasi. Seiring dengan berkembangnya teknologi handphone bisa dimanfaatkan untuk mencari informasi dari internet melalui fasilitas General Packet Radio Service (GPRS) \& Wireless Aplication Protocol (WAP) yang dimilikinya.

Teknologi WAP merupakan sebuah metode untuk menghadirkan halaman web didalam handphone / telepon genggam. Dengan begitu, maka bentuk informasi tidak harus ditampilkan dengan metode web yang hanya dapat diakses melalui browser, akan tetapi dapat ditampilkan dalam bentuk WAP melalui handphone, sehingga untuk 
mengakses informasi dapat dilakukan kapan saja dan dimana saja tidak tergantung oleh lokasi dan keberadaan PC.

Dengan melihat permasalahan yang ada dan seiring berkembangnya Teknologi WAP disertai dengan adanya dukungan GPRS dari handphone, oleh karena itu penulis mengambil judul penelitian "RANCANG BANGUN APLIKASI PENCARIAN ALAMAT di KABUPATEN KUNINGAN BERBASIS MOBILE”.

\section{Rumusan Masalah}

1. Bagaimana analisis dan perancangan dan pemodelan basis data untuk sistem pembangunan mobile web pencarian alamat di kabupaten Kuningan ?

2. Tools / model apa yang digunakan untuk merancang aplikasi WAP tersebut?

3. Bagaimana membangun program aplikasi WAP yang mampu diakses melalui handphone yang mempunyai kemampuan transmisi data dengan menggunakan PHP, WML dan MySQL ?

\section{Batasan Masalah}

Batasan masalah yang akan dibahas dalam penelitian penelitian ini adalah :

1. Pemodelan jaringan melalui selular WAP-GPRS, dengan tools yang menggunakan PHP, WML, dan MySQL.

2. Pengaksesan layanan informasi pencarian alamat menggunakan teknologi WAP meliputi alamat-alamat fasilitas umum, diantaranya alamat hotel, alamat rumah sakit, Sistem Pengisian Bahan Bakar Umum (SPBU), alamat perguruan tinggi, dan alamat kantor pemerintahan..

3. Hak Akses :

a. Admin dapat melakukan pengolahan data pada basis data.

b. Pengguna / user dapat melakukan pencarian alamat di kabupaten Kuningan dengan menggunakan handphone yang mempunyai kemampuan transmisi data.

\section{Metode Penelitian}

Metodologi adalah suatu metode-metode atau prosedur-prosedur atau konsep-konsep pekerjaan, aturan-aturan yang akan digunakan sebagai pedoman bagaimana dan apa yang harus dikerjakan selama pengembangan sistem. (Zainal A. Hasibuan, $\mathrm{PhD}, 2007: 14)$.

Metode yang dilakukan adalah dengan pendekatan metode Linear Sequential Model / Waterfall Model. Model ini adalah model klasik yang bersifat sistematis, berurutan dalam membangun software. Berikut ini gambaran dari waterfall model menurut referensi Ian Sommervill.

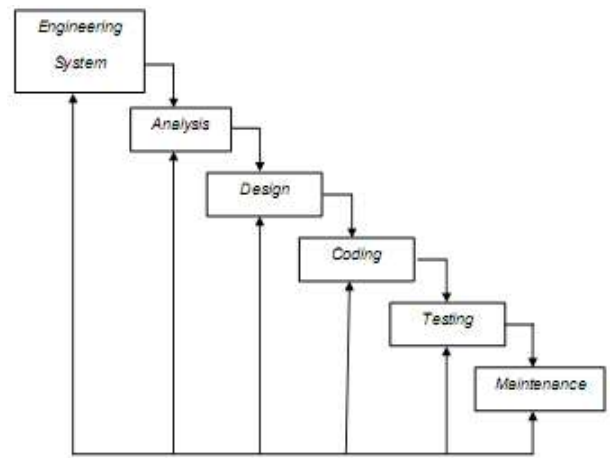

Gambar 1.1 Waterfall (Sommerfille, 2010)

a. System Enginerring adalah tahap observasi dimana metode ini digunakan untuk mendapatkan data-data di lapangan.

b. Analysis adalah mengumpulkan kebutuhan dan memahami sistem yang akan diimplementasikan secara lengkap kemudian dianalisis dan didefinisikan kebutuhan yang harus dipenuhi oleh rancang bangun sistem.

c. Design adalah mengevaluasi alternative design untuk sistem, membuat spesifikasi detail design, memenuhi kebutuhan dan pemecahan masalah yang sudah ditentukan.

d. Coding adalah mengimplementasikan hasil perancangan menjadi sebuah perangkat lunak dengan menggunakan bahasa pemrograman PHP dan MySQL sebagai database.

e. Testing adalah tahap pengujian digunakan untuk menemukan kesalahan program dan memastikan bahwa input data ke dalam perangkat lunak akan 
memberikan hasil yang sesuai dengan yangdibutuhkan. Pengujian yang dilakukan menggunakan teknik blackbox testing.

f. Maintenance adalah tahap pemeliharaan perangkat lunak yang telah selesai dibuat, dan perangkat lunak yang dibuat dapat mengalami perubahan sesuai permintaan dari pengguna.

\section{Tujuan Penelitian}

Tujuan dari penelitian yang dilakukan oleh penulis adalah merancang sistem pembangunan pencarian alamat di kabupaten Kuningan berbasis mobile dengan memanfaatkan teknologi WAP dan GPRS dengan menggunakan pemrograman PHP, WML dan MySQL.

\section{A. Wireless Application Protocol (WAP)} WAP (Wireless Application Protocol) merupakan suatu protokol komunikasi aplikasi, merupakan suatu arsitektur komunikasi yang dirancang untuk jaringan wireless. Sehingga dengan adanya teknologi WAP memungkinkan internet dapat diakses oleh perangkat wireless lainnya. WAP membawa informasi secara online melewati internet langsung menuju ke ponsel atau klien lainnya. Dengan adanya WAP berbagai informasi dapat diakses setiap saatnya dengan menggunakan ponsel.

WAP merupakan suatu standar protocol yang dibuat untuk mengatasi keterbetasan dari wireless devices seperti telepon selular dan PDA, keterbatasan itu antara lain :

A. Bandwith yang rendah,

B. Kemampuan CPU yang rendah,

C. Memori yang kecil,

D. Tampilan yang terbatas,

E. Catudaya (baterai) yang minimal,

F. Peralatan input yang berbeda

\section{Arsitektur WAP}

Ketika mobile device ingin dikoneksikan ke internet, semua komunikasi melalui WAP gateway, WAP gateway ini akan menerjemahkan semua protocol yang digunakan di Internet. Wireless Markup Language (WML) adalah suatu lingkungan yang dapat diperluas dan scalable untuk pengembangan aplikasi pada perangkat komunikasi mobile.

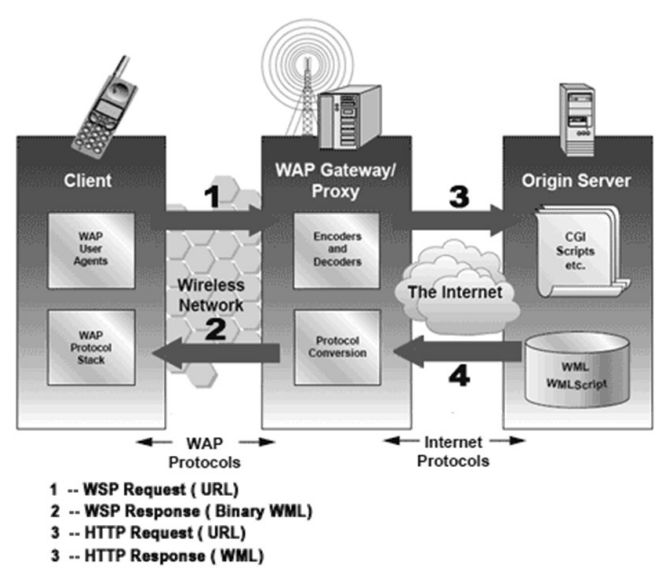

Gambar 2.1 Arsitektur WAP

Jenis isi WAP dan protocol telah dioptimalkan untuk perangkat wireless hanheld. WAP menggunakan teknologi proxy biasanya dikompres mengikuti fungsionalitasnya :

A. Protokol gateway - protocol ini menerjemahkan permintaan dari stack protocol WAP (WSP, WTP, WTLS, dan WDP).

B. Isi encoder dan decoder - isi decoder menerjemahkan isi WAP, halaman WML, dan program WMLScript ke dalam format yang disandikan untuk mengurangi ukuran data pada wireless network.

Protokol dapat didefinisikan sebagai suatu cara atau aturan yang dibakukan untuk melakukan komunikasi antara satu peralatan jaringa (bisa berupa computer, switch, hub, dan lain-lain) dengan peralatan jaringan lainnya.

\section{B. Perancangan Sistem}

Setelah tahap analisis sistem selesai dilakukan, maka analis sistem telah mendapatkan gambaran dengan jelas apa yang harus dikerjakan. Analis sistem harus memikirkan bagaimana membentuk sistem tersebut. Tahap ini disebut dengan perancangan sistem.

Pada awalnya perancangan database seorang analisis sistem dianjurkan untuk membuat Diagram Konteks, Diagram Aliran Data (Data Flow Diagram/DFD), Entity 
Relationship Diagram (ERD), dan relasi antar tabel.

\section{Diagram Konteks}

Diagram Konteks adalah sebuah diagram sederhana yang menggambarkan suatu sistem informasi secara global, termasuk aliran data dari masukan (input) dan keluaran (output) menjadi sebuah informasi yang terpadu.

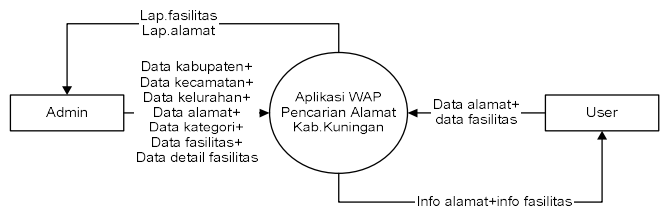

Gambar 3.4 Diagram Konteks

\section{DFD Level 0}

Data Flow Diagram merupakan gambaran sistem secara logika tanpa mempertimbangkan lingkungan fisik dimana data tersebut mengalir atau disimpan. DFD merupakan alat yang dapat mengambarkan arus data di dalam sistem secara terstruktur dan jelas. DFD level 0 untuk Sistem Informasi Pengelolaan Data Ayam Petelur terdapat pada gambar 3.5 dibawah ini.

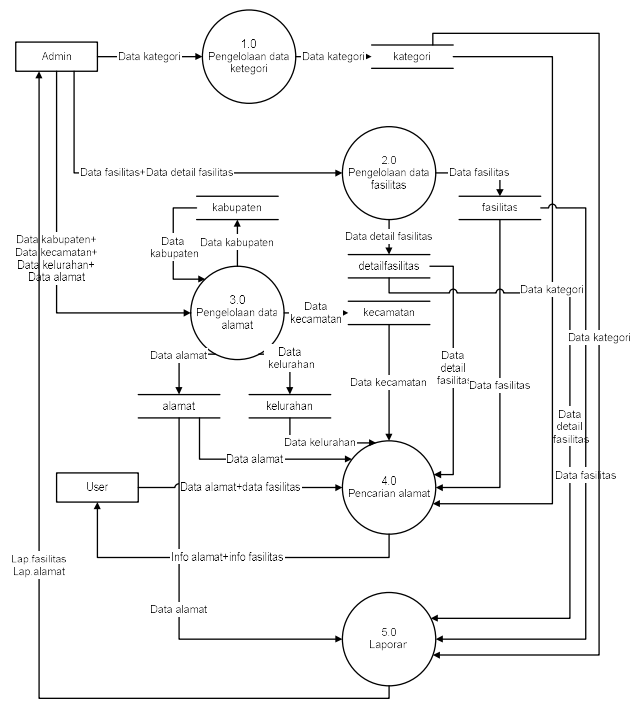

Gambar 3.5 DFD level 0

Proses 1.0

Proses 1.0 yaitu proses pengelolaan data kategori dilakukan oleh admin untuk mengelompokan data fasilitas kedalam kategori. Data kategori akan disimpan kedalam tabel kategori.

\section{Proses 2.0}

Proses 2.0 yaitu proses pengelolaan data fasilitas dilakukan oleh admin untuk menampilkan data fasilitas secara detail pada proses pencarian alamat. Data fasilitas disimpan kedalam tabel fasilitas.

Proses 3.0

Proses 3.0 yaitu proses pengelolaan data alamat dikelola oleh admin. Data alamat akan dijadikan sebagai master data alamat yang akan ditampilkan pada proses pencarian alamat beserta dengan fasilitas.

Proses 4.0

Proses 4.0 yaitu proses pencarian alamat dilakukan oleh user pada proses penggunaan aplikasi WAP. User dapat memilih data fasilitas atau data kategori pada menu browser WAP.

Proses 5.0

Proses 5.0 yaitu proses laporan yang akan diberikan kepada bagian admin berasal dari semua tabel yang ada.

\section{E. Entity Relationship Diagram (ERD)}

Pada model Entity-Relationship semesta data yang ada di dunia nyata diterjemahkan menjadi sekumpulan obyek dasar yang disebut entitas (entity) dan relasi antara obyek-obyek tersebut (relationship). Kedua komponen dasar ini didepenelitiankan lebih jauh melalui sejumlah atribut. Entity Relationship diagram (Diagram E-R) adalah gambaran keseluruhan struktur logis dari sebuah basis data.

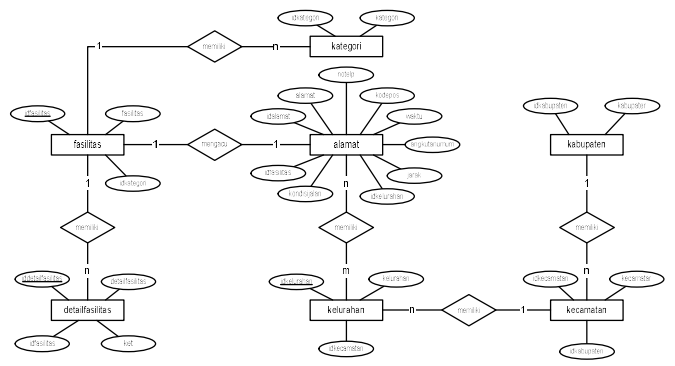

Gambar 3.6 ERD

\section{Implementasi Sistem}

Implementasi adalah tahap penerapan hasil perancangan yang prosesnya diuraikan sebelumnya. Implementasi yang dilakukan antara lain adalah menerapkan perancangan 
antarmuka ke dalam bentuk aplikasi, perancangan struktur data kedalam bentuk tabel database, pembuatan kode program dan sebagainya.

\section{Perangkat Implementasi}

Penjelasan perangkat implementasi bertujuan agar diketahui perangkat keras dan perangkat lunak yang mendukung perangkat implementasi dari sistem yang dirancang.

\section{Spesifikasi Perangkat lunak}

Dalam pembuatan Aplikasi WAP Pencarian Alamat ini, perangkat lunak yang penulis gunakan diantaranya adalah sebagai berikut :

1. Xampp sebagai web server yang menyertakan didalamnya phpmyadmin sebagai pengolah database.

2. Macromedia Dreamweaver 8 sebagai editor PHP dengan dukungan IDE dan fasilitas lainnya.

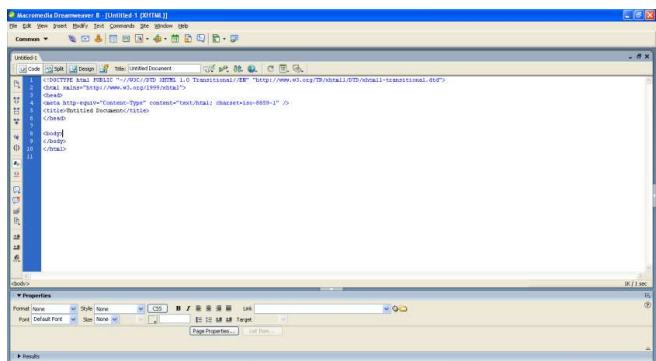

Gambar 4.1 Macromedia Dreamweaver 8

3. Mozilla Firefox sebagai web browser.

\section{Spesifikasi Perangkat Keras}

Perangkat keras yang digunakan oleh penulis didalam pembangunan Aplikasi WAP Pencarian Alamat ini diantaranya adalah sebagai berikut :

1. Intel Pentium 4 prosesor P6000 $(1,86$ Ghz)

2. DDR $31 \mathrm{~Gb}$.

3. HDD $320 \mathrm{~Gb}$.

4. Intel HD Graphics.

5. HD LED LCD 14".

Sedangkan PC minimal yang dapat digunakan untuk menjalankan Aplikasi WAP Pencarian Alamat ini spesifikasinya sebagai berikut :

1. Intel Pentium II atau setara.

2. Ram $64 \mathrm{Mb}$.

3. Hardisk $800 \mathrm{Mb}$.
4. Monitor VGA.

5. CDRom..

\section{Antar Muka (interface) program}

Pada tahap implementasi, untuk menjalankan program yaitu dengan menjalankan web browser kemudian ketikan http://localhost/wapalamat sistem akan menampilkan tampilan index pada gambar dibawah ini.

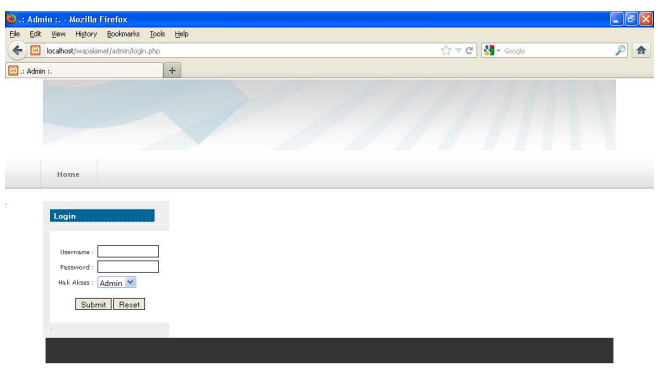

Gambar 4.2 Halaman login

\section{Data Kategori}

Pada tampilan data kategori akan dikelola oleh admin kemudian akan disimpan pada tabel kategori. Data kategori digunakan untuk mengelompokan data fasilitas ke dalam kategori tertentu.

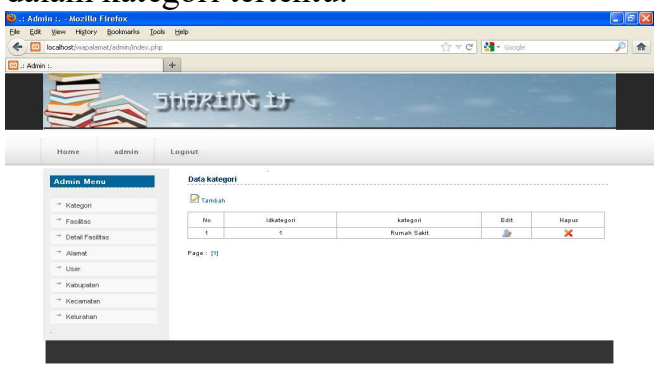

Gambar 4.3 Data Kategori

\section{Data Fasilitas}

Tampilan data fasilitas dikelola oleh admin untuk mengelola fasilitas yang akan ditampilkan pada halaman WAP. Data fasilitas akan disimpan pada tabel fasilitas. 


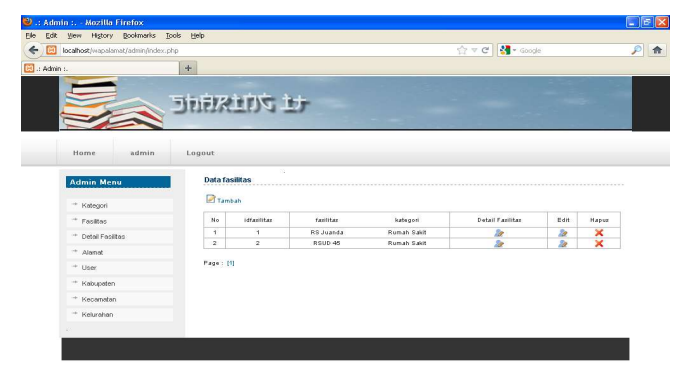

Gambar 4.4 Data Fasilitas

Data Alamat

Tampilan data alamat dikelola oleh admin untuk ditampilkan pada halaman WAP. Data halaman yang akan digunakan pada proses pencarian alamat berdasarkan fasilitas dan kategori tertentu. Data alamat akan disimpan pada tabel alamat.

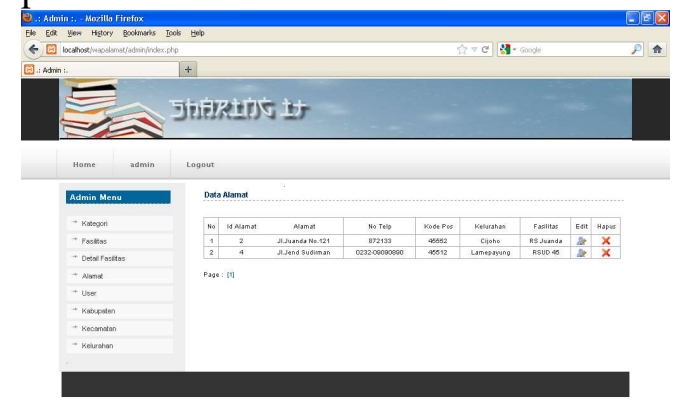

Gambar 4.6 Data Alamat

\section{Data User}

Tampilan data user digunakan oleh admin sebagai pengelolaan data user yang bisa melakukan akses terhadap sistem. Data user akan disimpan pada tabel user.

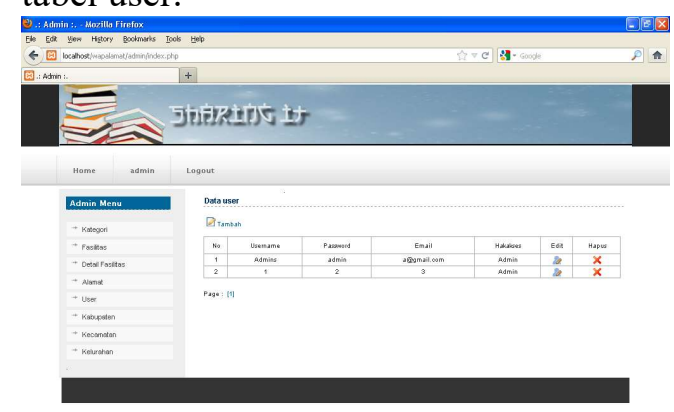

\section{Data Kabupaten}

Tampilan data kabupaten digunakan untuk mengelola data kabupaten yang akan digunakan untuk proses identifikasi kabupaten pada tabel kecamatan.

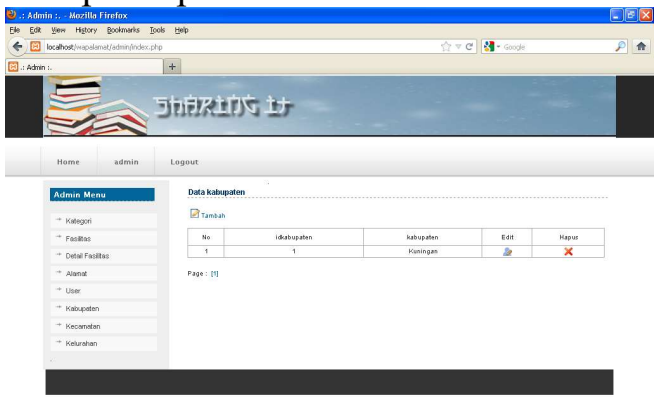

\section{Gambar 4.8 Data Kabupaten}

\section{Data Kecamatan}

Tampilan data kecamatan dikelola oleh admin untuk mengelola data kecamatan yang akan digunakan pada tampilan WAP. Data kecamatan akan digunakan pada proses pencarian alamat berdasarkan kecamatan tertentu.

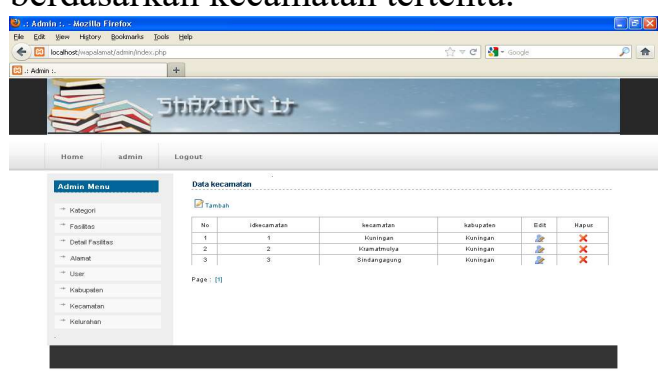

Gambar 4.9 Data Kecamatan

\section{Data Kelurahan}

Tampilan data kelurahan digunakan untuk mengelola data kelurahan untuk proses identifikasi alamat berdasarkan kelurahan. Data kecamatan akan digunakan sebagai acuan jarak dan kordinat yang akan ditampilkan per alamat kelurahan.

\section{Gambar 4.7 Data User}




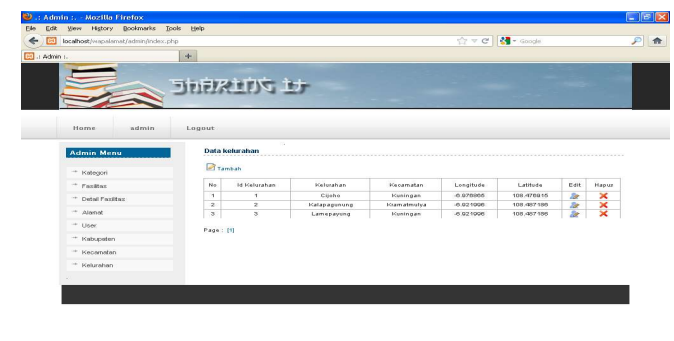

Gambar 4.10 Data Kelurahan

\section{Tampilan Index WAP}

Pada tahap implementasi, untuk menjalankan program yaitu dengan menjalankan wap emulator kemudian ketikan http://localhost/wapalamat sistem akan menampilkan tampilan index wap pada gambar dibawah ini.

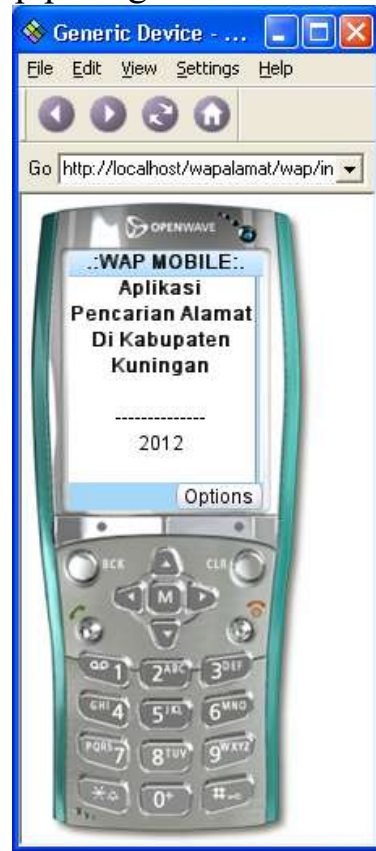

Gambar 4.11 Tampilan Index WAP

\section{Menu WAP}

Tampilan menu WAP akan menampilkan menu pilihan user, untuk memilih link user hanya melakukan pilih select pada kontrol navigasi kemudian pilih select.

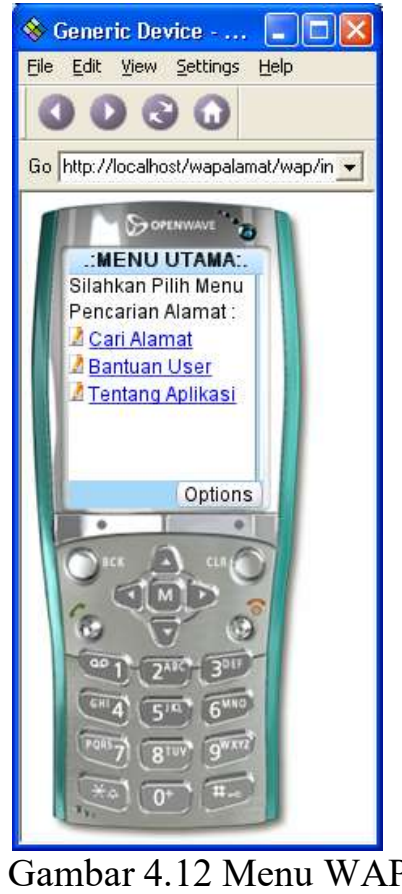

\section{Tampilan Alamat}

Tampilan alamat akan menampilkan alamat fasilitas secara detail. User dapat melihat alamat lebih detail dan penentuan posisi user dengan fasilitas berdasarkan alamat dan kordinat fasilitas.

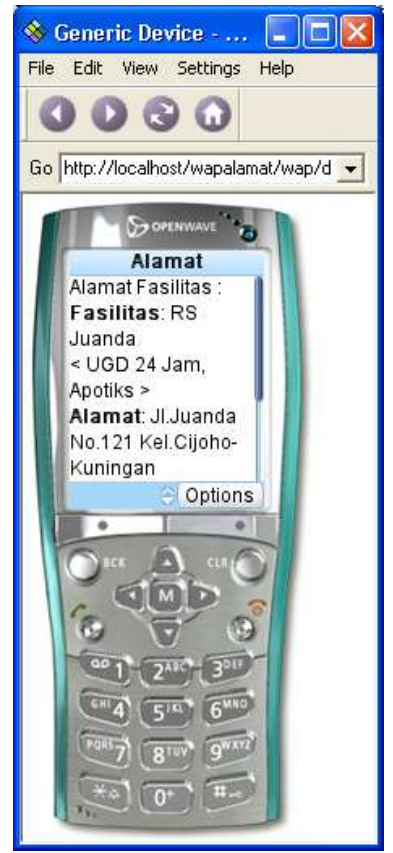

Gambar 4.16 Tampilan Alamat 


\section{Tampilan Alamat Kordinat}

Tampilan alamat kordinat digunakan untuk menampilkan data alamat berdasarkan kordinat tertenu sesuai dengan data kelurahan, kordinat akan ditampilkan pada maps sesuai dengan posisi fasilitas.

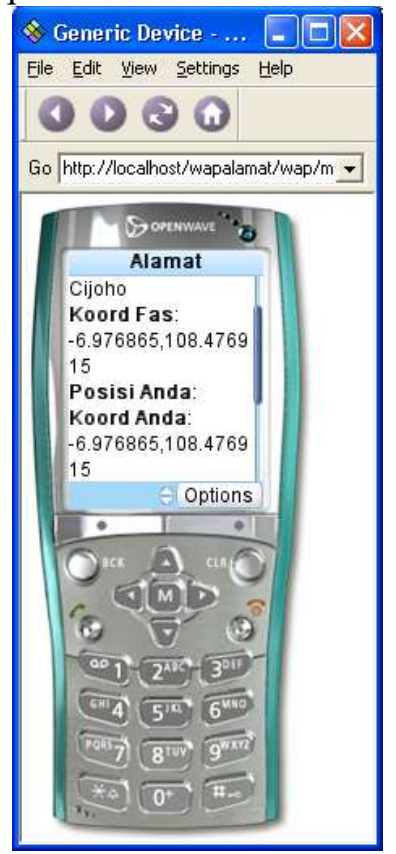

Gambar 4.17 Tampilan Alamat Kordinat

\section{Penutup}

\subsection{Kesimpulan}

Adapun kesimpulan yang diperoleh dari hasil penelitian yang telah dilakukan didalam membuat Aplikasi Pencarian Alamat Berbasis WAP adalah sebagai berikut :

1. Sistem yang dibuat memberikan kemudahan didalam proses pencarian alamat fasilitas yang ada di Kabupaten Kuningan.

2. Sistem yang dibuat mampu memberikan kemudahan dialam pencarian alamat karena dilengkapi dengan fasilitas googlemap dan tata letak kordinat fasilitas.

3. Aplikasi yang berbasis WAP sehingga dapat memberikan kemudahan untuk melakukan akses dimanapun.

4. Admin dapat mengelola dengan baik proses input data, administrasi, dan pelaporan data

\subsection{Saran}

Setelah penulis mengadakan penelitian, maka ada beberapa saran yang ingin penulis kemukakan agar sistem berjalan maksimal, antara lain:

1. Untuk mengoperasikan program aplikasi ini, diperlukan adanya pelatihan khusus terlebih dahulu terhadap user.

2. Untuk menghasilkan program aplikasi yang baik, diperlukan ketelitian dalam penelitian, perancangan, dan pengkodean.

3. Data yang telah terkomputerisasi diharapkan merupakan data yang up to date.

4. Pengisian data untuk semua format masukan harus dilakukan dengan teliti sehingga informasi yang dihasilkan sesuai dengan yang diharapkan.

5. Dalam pembuatan aplikasi ini masih banyak sekali kekurangan, oleh karena itu diperlukan adanya pengembangan yang lebih lanjut.

\section{DAFTAR PUSTAKA}

- Fathansyah,Ir.( 2002) Basis Data, Informatika Bandung

- Kadir, Abdul. (2001). Dasar Pemrogaman Web Dinamis Menggunakan PHP, Yogyakarta,Penerbit Andi

- Kadir,A.(2001).Dasar Pemograman Web Dinamis Menggunakan PHP, Yogyakarta,Penerbit Andi

- Kadir,A.(2008)Dasar Perancangan dan implementasi, Yogyakarta

- Kamus Besar Bahasa Indonesia, PT.Elex Media Komputindo, Jakarta, 2002.

- Jogiyanto Hartono, MBA,Ph.D.Akt, Analisa dan Desain Sistem Informasi,Yogyakarta, 2000.

- Nugroho, Bunafit. (2005). Pengembangan Program WAP dengan WML \& PHP. Yogyakarta,Penerbit Andi

- Susanto,A.(2002) Analisa Dan Penerapan Sistem, Yogyakarta,

- Data Kecamatan dan Kelurahan [online], ( http://kuningankab.go.id/ ), 19 November 2012 Jam 2:04. 